\title{
Requisitos para 0 design de um artefato digital de suporte à gestão de resgate $e$ adoção de animais
}

\author{
Requirements for design of \\ a digital artifact to support \\ animals rescue and adoption
}

Priscila Cristiane Bandeira de Melo $^{[1]}$, Bruno Santana da Silva ${ }^{[2]}$

\begin{abstract}
Resumo: Este trabalho relata um estudo de caso que investigou em profundidade atividades e informações envolvidas no processo de resgate e adoção de animais. Fluxogramas e dicionário de dados foram elaborados, discutidos e revisados em grupos focais com participantes de um projeto de extensão universitária. Como resultado, foram identificados 41 requisitos funcionais para orientar o design de um artefato digital de apoio à gestão do resgate e adoção de animais. Destes, 21 requisitos foram priorizados para a primeira versão do artefato digital, também chamada de mínimo produto viável. Os resultados deste trabalho servem como importante subsídio para a concepção futura do processo de interação e interface de um artefato que permita ao usuário usufruir dos benefícios das tecnologias digitais com uma boa experiência de uso.
\end{abstract}

Palavras-chave: Grupo focal. Informações. Atividades. Fluxograma.

Abstract: This work reports a case study that investigated in depth activities and information involved in animals rescue and adoption process. Flowcharts and data dictionary were developed, discussed and revised in focus groups with participants in a university extension project. As a result, 41 functional requirements were iden-

[1] Bacharel em Design, UFRN. pribmrn@gmail.com

[2] Doutor em Informática, PUC-RIO.bruno@imd.ufrn.br 
tified to guide the design of a digital artifact to support animal rescue and adoption management. Of these, 21 requirements were prioritized for the digital artifact first version, also called the minimum viable product. The results of this work serve as an important subsidy for the future conception of the interaction process and interface of an artifact that allows the user to enjoy the benefits of digital technologies with a good user experience.

Keywords: Focus group. Information. Activities. Flowchart.

\section{INTRODUÇÃO}

Conviver em harmonia com uma grande população de animais domesticados requer cuidados de toda a sociedade. Entre eles, existem cães e gatos domiciliados, que vivem junto com seus tutores, e aqueles que vivem em condição de abandono nas ruas. Segundo pesquisa realizada pelo Instituto Pet Brasil (2019), cães e gatos constituem 78,1 milhões de animais domiciliados em território nacional. Já a World Animal Protection (2019), organização internacional que trabalha pelo fim do sofrimento desnecessário dos animais, afirma existir mais de 30 milhões de cães e gatos vivendo nas ruas brasileiras.

Esses animais costumam se reproduzir rapidamente e podem causar desequilíbrio ambiental. Eles podem transmitir várias doenças aos seres humanos (zoonoses), ameaçando a saúde pública (JOFFILY et al., 2013). Para evitar isso, são necessárias ações do Estado e de cada cidadão individualmente. Ações comuns do Poder Público consistem em castração e vacinação realizados pelos Centros de Controle de Zoonoses nos municípios. Os cidadãos também podem ter atitudes individuais preventivas, como levar para vacinar e castrar seus animais, além de não os abandonar. A prática do abandono, inclusive, está prevista como infração no artigo 164 do Código Penal (BRASIL, 1940).

A adoção de animais é outra atitude individual que pode contribuir para evitar essas situações indesejadas. Contudo, é comum as pessoas terem dúvidas e dificuldades sobre a retirada de um animal da rua, tais como: Onde há animais abandonados? Como capturar? Que animais estão disponíveis para adoção? Como saber se o animal está saudável? e 
Quais itens são essenciais para receber o animal adotado? Os abrigos, Organizações Não Governamentais (ONGs) e grupos informais podem exercer papel fundamental para apoiar esse processo. De acordo com o Instituto Pet Brasil (2019), estima-se que existam 370 ONGs de proteção animal no Brasil. O Instituto LuisaMell (2021) e o Clube dos Vira-Latas (2021) são exemplos de ONGs de repercussão nacional.

O resgate e a adoção de animais geralmente envolvem adotantes e voluntários organizados em grupos informais ou em ONGs. Eles cooperam dispersos geograficamente, trocando informações sobre pessoas e animais envolvidos. Para tanto, ferramentas de gestão de informações offline, como papéis e pastas, e online, como softwares de edição de texto e de planilhas eletrônicas são utilizados para administrar esse trabalho colaborativo. Mesmo assim, permanecem dificuldades para organizar e ter acesso rápido e fácil às informações necessárias em cada momento, pois estas ficam dispersas em vários documentos e em vários locais. Ainda existe espaço para se desenvolver ferramentas que oferecerão um apoio melhor para as pessoas colaborarem, se comunicarem e coordenarem a execução de atividades (PIMENTAL; FUKS, 2011) no processo de resgate e adoção de animais.

O trabalho do designer concentra-se em compreender uma realidade, identificar oportunidades de melhoria nela, conceber uma intervenção e avaliar seus impactos nessa realidade (SCHÖN, 1983; LAWSON, 2006; BONSIEPE, 2015). Para trazer uma contribuição da área de Design para os animais domésticos que vivem nas ruas e evitar as consequências negativas disso, este trabalho tem por objetivo investigar requisitos de um artefato digital para apoiar o processo de resgate e adoção de animais. A capacidade de processamento de dados, comunicação pela internet e a integração entre diferentes dispositivos tornam um artefato digital promissor para apoiar o trabalho colaborativo disperso geograficamente como ocorre nesse caso. 


\section{ELEMENTOS ENVOLVIDOS NO DESIGN DE ARTEFATO DIGITAL}

Bonsiepe (2015) argumenta que usuários, tarefas, artefatos e a interface entre eles são elementos fundamentais da ontologia do Design. Os estudos de Interação Humano-Computador (BARBOSA; SILVA, 2010) detalham os elementos que deveriam ser considerados durante o processo de design de um artefato digital.

A partir de ideias abstratas na mente das pessoas, Garrett (2013) evidencia as necessidades dos usuários e os objetivos do produto como elementos que motivam o uso do artefato digital (estratégia). Essas motivações serão mapeadas para funcionalidades e conteúdos informacionais presentes no artefato (escopo). Como essas funcionalidades e conteúdos costumam ser em grande quantidade, eles precisam ser organizados em um processo de interação e na arquitetura de informação (estrutura) para auxiliar a cognição das pessoas. Isso vai se tornando concreto com a definição de porções da interface (por exemplo, tela, janela ou página) com informações bem organizadas internamente (e.g. agrupadas em cabeçalho, corpo ou rodapé), sendo possível navegar entre elas (esqueleto). Por fim, a interface (superfície) define como as informações e as funcionalidades serão representadas (e.g. cor, forma, tamanho, tipografia, etc.).

Silva (2010) faz outra leitura dos elementos envolvidos na interação dos usuários com um artefato digital. Na visão dele, o uso de um artefato digital ocorre por meio de um processo de interação entre o usuário e a interface desse artefato, dentro de um contexto de uso, orientado por objetivos do usuário e expresso pelo domínio (vocabulário utilizado para descrever as atividades das pessoas). Durante o processo de interação, o usuário associa seus objetivos à sequência de ações na interface do artefato digital. Depois que o usuário realiza uma ação sobre a interface, o artefato lhe dará uma resposta por esse mesmo meio. Dessa forma, o projeto tanto do processo de interação quanto da interface é de responsabilidade do designer. 
O designer precisa conhecer os elementos envolvidos com um artefato digital para ter boas condições de projetá-lo (SCHÖN, 1983; LAWSON, 2006; BONSIEPE, 2015). Na visão de Garret (2013) e de Silva (2010), os objetivos dos usuários e, consequentemente, às atividades associadas, bem como os dados (informações ou vocabulário) utilizados para falar sobre esses objetivos e atividades são elementos importantes para um designer conhecer durante o processo de design digital.

\section{TRABALHOS RELACIONADOS}

Trabalhos anteriores já abordaram a causa animal. Alguns concentraram-se apenas no design de marcas de ONGs (CUNHA, 2016; BRAUN; GOMEZ, 2010). Outros se dedicaram ao design de artefatos digitais com diferentes abordagens. Ponzi (2015) e Corrêa e Sanches (2015) relatam o design de websites para divulgar trabalhos realizados pelas ONGs. Marques (2018) apresentou o design de um site para denúncias de maus-tratos a animais.

Também é possível encontrar trabalhos dedicados ao design de artefatos digitais que apoiam de algum modo o processo de resgate e adoção de animais (JAGHER et al., 2019; SILVA et al., 2019; SILVA FILHO, 2017; MENDES et al., 2016; SILVA, 2016; NUNES, 2014). Esses trabalhos abordam a promoção da adoção de animais, a troca de mensagens, doações e parcerias. Porém, o processo de resgate e adoção vai bem além dessas atividades. Apenas Mendes (et al., 2016) tratou também do resgate, do cuidado temporário e do transporte envolvidos nesse processo. Ainda assim, este trabalho não investigou em profundidade o processo de resgate e adoção de animais para suportar o design de um artefato digital.

Os trabalhos relacionados geralmente tratam o resgate e a adoção como ações individuais voluntárias com animais perdidos e encontrados, em vez de um processo com atividades ordenadas executado por grupos organizados como ONGs. O design de um artefato digital para apoiar a gestão e a comunicação de pessoas realizando um trabalho colaborativo de resgate e adoção de animais ainda requer uma investigação mais detalhada deste processo. 


\section{ESTUDO DE CASO}

Uma boa compreensão do processo de resgate e adoção de animais oferecerá suporte ao design de artefatos digitais para gestão deste trabalho colaborativo. Com a intenção de contribuir com tal compreensão, este trabalho realizou um estudo de caso com um grupo organizado de voluntários engajados na causa animal. Este grupo promove resgate e adoção de gatos em Natal, Rio Grande do Norte, como parte de sua atuação em um projeto de extensão da Universidade Federal do Rio Grande do Norte - UFRN. São aproximadamente 50 voluntários que realizam atividades colaborativas semelhantes ao trabalho de ONGs de proteção animal. A maior parte dos voluntários são estudantes de graduação em diferentes cursos, como Administração, Design, Computação, Ciências Biológicas, Zootecnia e Enfermagem. Apesar do foco de atuação do projeto ser os gatos, este trabalho os interpretou de uma forma mais abstrata como sendo qualquer animal doméstico que costuma ser abandonado na rua. Assim, os resultados encontrados poderão ser uteis em mais situações.

$\mathrm{O}$ estudo de caso foi realizado em 3 etapas. Na primeira etapa, os pesquisadores registraram sua compreensão sobre o processo de resgate e adoção de animais em fluxogramas (MORAES; MONT'ALVÃO, 2009) e em dicionário de dados (WIEGERS; BEATTY, 2013). Esse dicionário enumera e explica o vocabulário utilizado pelas pessoas para falarem sobre determinado assunto ou atividade. O registro permitiu aproveitar conhecimentos e experiências de alguns pesquisadores há bastante tempo envolvido com a causa animal e que colaboravam com o grupo de voluntários no projeto de extensão abordado. Além disso, o exercício de construir uma representação do que se conhece está em linha com a conversa com materiais e a reflexão em ação de Schön (1983), trazendo muitos benefícios ao processo de design pelo aprimoramento da compreensão do designer sobre o problema de design e a solução sendo concebida. 
Os fluxogramas e dicionário de dados elaborados pelos pesquisadores serviram de base para a realização da segunda etapa do estudo de caso, quando foi realizado um grupo focal (BARBOSA; SILVA, 2010; COURAGE; BAXTER, 2005) com voluntários do projeto de extensão e feitas revisões necessárias nessas documentações para refletirem uma visão mais coletiva. Participaram deste grupo focal 4 voluntários da equipe operacional de resgate e adoção, 2 voluntários da equipe de Computação, além de 2 pesquisadores. Os participantes foram escolhidos pela visão complementar aos pesquisadores e pelo potencial que apresentavam para contribuir com a compreensão do processo de resgate e adoção e com a definição dos requisitos do artefato a ser projetado. Em função da pandemia da Covid-19, o grupo focal foi realizado de forma remota por meio de videochamada gravada no Google Meet em uma única sessão. Enquanto o conteúdo do dicionário de dados e dos fluxogramas era descrito para os participantes, buscou-se confirmar ou corrigir esses registros a partir das falas e discussões dos participantes. Como resultado, alguns dados foram adicionados ao dicionário e algumas atividades foram acrescidas aos fluxogramas. Como base na compreensão resultante dessa revisão feita neste grupo focal, os pesquisadores elaboraram uma proposta inicial de requisitos funcionais para o artefato digital.

A lista inicial de requisitos funcionais, os fluxogramas e o dicionário de dados revisados serviram de base para a terceira e última etapa do estudo de caso. Nesta etapa foi realizado um novo grupo focal por videoconferência com voluntários do projeto de extensão. As discussões ocorreram em duas sessões, com intervalos de quase um mês entre elas. Além de 2 pesquisadores, 5 voluntários da equipe de Computação discutiram e revisaram os fluxogramas, dicionário de dados e requisitos funcionais. Por fim, eles priorizaram os requisitos funcionais que deveriam compor o MVP (MinimumViableProduct) para que o artefato digital possa ser desenvolvido com maior celeridade, mas permitindo a realização de tarefas essenciais de gestão do processo de resgate e adoção de animais. 


\section{RESULTADOS}

O estudo de caso resultou em uma melhor compreensão sobre (1) o processo colaborativo de resgate e adoção registrado em fluxograma e sobre (2) as principais informações utilizadas nesse processo. Além disso, foram definidos 41 requisitos funcionais para o artefato digital e priorizados 21 requisitos funcionais para a primeira versão deste artefato, que formarão o MVP.

O resgate e adoção de animais neste estudo foi realizado por um grupo organizado em um projeto de extensão universitária. Como o trabalho coletivo neste projeto seria muito semelhante ao trabalho de outros grupos organizados, o termo projeto utilizado na descrição dos resultados abaixo pode ser considerado como sinônimo de ONGs ou grupos organizados envolvidos com a causa animal. Os membros do projeto se estruturam em equipes, como a equipe responsável pelo resgate e adoção de animais e a equipe de marketing digital, por exemplo.

A Figura 1 apresenta o processo de resgate e adoção de animais de rua identificado neste estudo. Ele começa com o pedido de resgate, quando o autor envia a um membro do projeto um conjunto de informações sobre os animais a serem resgatados. A partir dessas informações, o líder da equipe avalia se o pedido de resgate se enquadra nos critérios de prioridade.

Em casos de resposta positiva ao pedido de resgate, é preciso definir as pessoas responsáveis por atendê-lo. Para isso, o líder de equipe solicita 2 membros do projeto para atenderem ao pedido de resgate dos animais. Depois é necessário definir um lar temporário para os animais resgatados. Para tanto, o líder de equipe solicita pelo menos 1 candidato a cuidador temporário cadastrado anteriormente para receber os animais. Tanto membros do projeto quanto voluntários externos podem se candidatar para oferecer lar temporário. Caso não haja cuidadores disponíveis ou respostas à solicitação de lar temporário feito a candidatos, é possível solicitar voluntários por meio das redes sociais do projeto. 
A próxima atividade é, então, a captura dos animais. Para essa tarefa, é possível que o voluntário responsável pelo resgate necessite pegar alguns materiais para realizar o resgate, como caixa de transporte, ração úmida ou seca, equipamentos de proteção contra arranhaduras, entre outros. Com os materiais necessários, o voluntário se dirige ao local indicado no pedido de resgate para capturar os animais. Caso não os encontre, a captura é adiada e o voluntário devolve os materiais de resgate ao estoque.

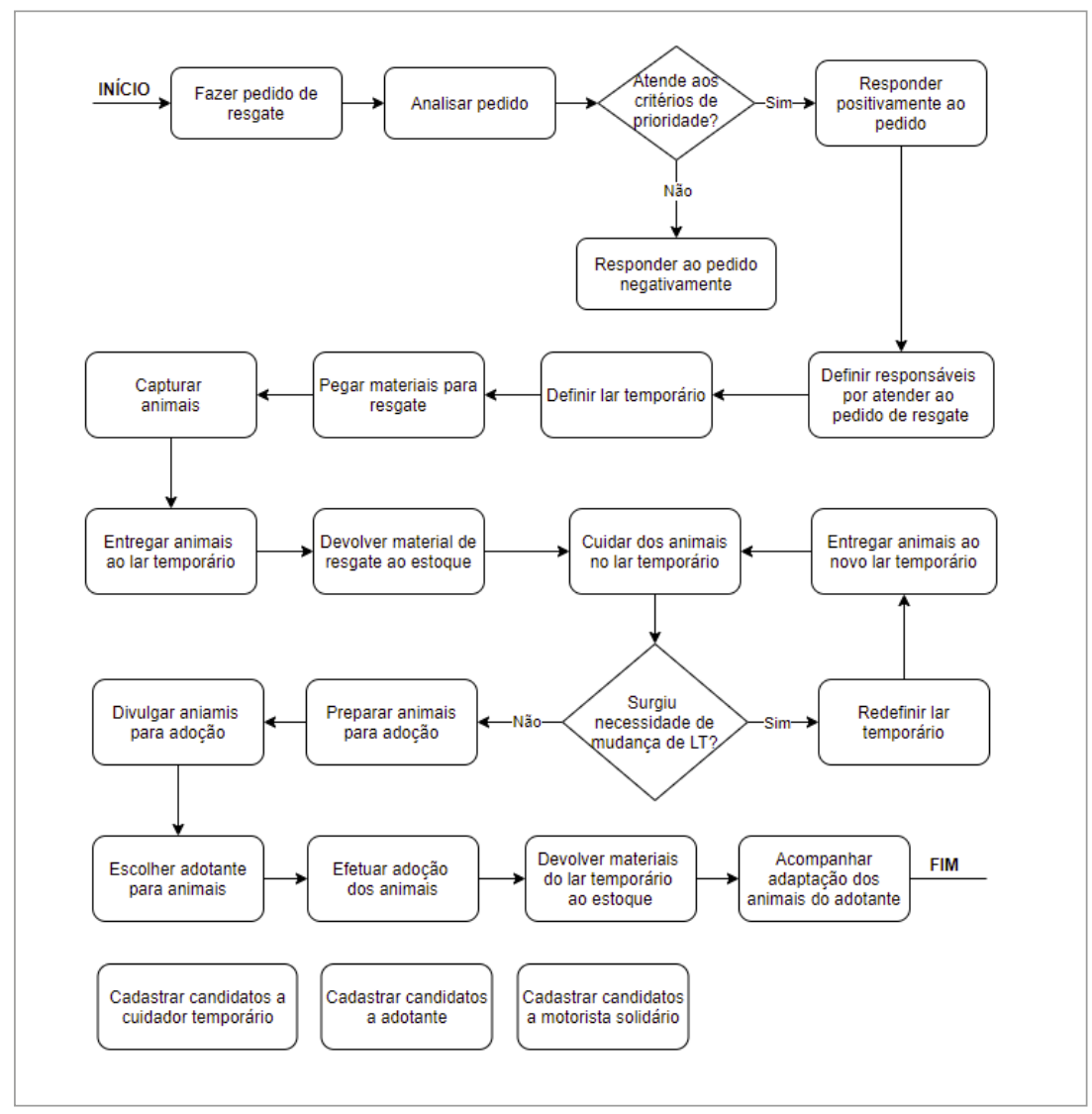

Figura 1. Fluxograma geral do processo de resgate e adoção de animais.

Após capturados, os animais precisam ser entregues ao lar temporário. Para isso, o membro da equipe de resgate solicita carona a um motorista solidário cadastrado ou de aplicativo de transporte existente no mercado. Tanto membros 
do projeto quanto voluntários externos podem se candidatar para oferecer carona solidária. Confirmada a disponibilidade de transporte, o voluntário dirige-se com os animais resgatados ao lar temporário, entregando-os ao cuidador que ficará responsável pelos seus cuidados. Depois de dar as orientações específicas sobre os animais resgatados, o voluntário registra detalhes sobre eles, confirma o prazo máximo referente à disponibilidade do lar temporário e, por fim, devolve ao estoque os materiais de resgate que não serão necessários durante o cuidado dos animais. Após o prazo máximo definido para os cuidados em um lar temporário específico ou em situações imprevistas, pode ser necessário efetuar mudança de lar temporário. O procedimento dessa mudança é similar ao transporte inicial de animais do local de resgate ao lar temporário.

Uma vez sob os cuidados do cuidador temporário, os animais são preparados para adoção. Eles são levados por um membro da equipe de resgate a uma consulta veterinária. Caso seja diagnosticado algum problema de saúde, é realizado o tratamento prescrito pelo médico veterinário. No lar temporário, os animais são vermifugados e, quando atingirem a idade adequada, assam por testes de doenças e castração. Quando o estado de saúde dos animais estiver estável, eles podem ser divulgados para adoção responsável. Para isso, um membro da equipe de resgate solicita a divulgação dos animais para adoção a um membro da equipe de marketing digital. Caso haja alguma mudança no status dos animais, como fuga ou óbito, uma solicitação análoga pode ocorrer para suspender a divulgação.

Após ser anunciada a disponibilidade dos animais para adoção, inicia-se oficialmente o período de cadastro para candidatos a adotantes. Um membro da equipe de resgate acessa a lista de candidatos a adotantes para identificar um adequado às condições previstas no Termo de Adoção Responsável, como morar em casa ou apartamento com janelas e outras rotas de fuga teladas, por exemplo. Uma vez encontrado um candidato adequado, é agendada uma data para entrega dos animais. 
No dia marcado, um membro da equipe de resgate prepara-se para efetuar a adoção dos animais. Para isso, primeiramente solicita carona e dirige-se ao lar temporário onde os animais estão sendo cuidados. Então, o membro do projeto recebe do cuidador temporário os animais e os materiais que ainda restam, como ração, potes, caixa de transporte, entre outros. Assim, ele leva os animais ao provável lar adotivo. 0 membro do projeto confirma pessoalmente se o local está de acordo com os critérios estabelecidos para receber os animais. Em caso negativo, os animais voltam ao lar temporário e identifica-se outro candidato a adotante adequado. Porém, em caso positivo, o adotante assina o Termo de Adoção Responsável e recebe os animais, sendo efetuada a adoção. Por fim, o membro da equipe de resgate devolve ao estoque os materiais que estavam no lar temporário e registra os transportes realizados. É importante observar que, para que essas atividades ocorram, entende-se a necessidade de efetuar cadastro de membros do projeto.

A Tabela 1 apresenta o dicionário de dados identificado neste estudo. Ele reúne as principais informações (coluna da esquerda) e atributos (coluna da direita) utilizadas no processo de resgate e adoção de animais. A maior parte dessas informações fazem parte do senso comum das pessoas em geral. Outros, por sua vez, podem ser desconhecidas daqueles que não têm muito contato com ações de proteção animal. É importante esclarecer 3 dessas informações aqui que representam colaborações específicas do processo de resgate e adoção de animais (SANTOS, 2015). O cuidador temporário é um voluntário (membros ou não do projeto) responsáveis pelos cuidados diários dos animais resgatados até a adoção. Essa prática é bastante comum para ONGs e grupos informais de protetores de animais que não possuem um abrigo para os animais resgatados. Estes, então, são levados ao lar temporário, ou seja, à residência do cuidador que se oferece para alimentar, prover água, medicar e brincar com os animais, entre outras atividades. O lar temporário é necessário 
até que a adoção seja confirmada. Outro colaborador importante neste processo é o motorista solidário, um voluntário que se oferece para fazer o transporte de animais em várias

Tabela 1. Dicionário de dados do processo de resgate e adoção.

\section{Atores}

Autor do pedido de resgate

Membro do projeto

Motorista solidário

Cuidador temporário

Adotante

me, telefone fixo, celular, número identidade, órgão expedidor, data de expedição, e-mail, lar adotivo, preferência para adoção (preferência por animais específico, preferência por animal com característica específica).

Membro do projeto ou pessoa externa ao projeto.

Líder de equipe; Responsável por analisar um pedido; Responsável pelo resgate; Responsável pela entrega ao lar temporário; Responsável pela entrega ao lar adotivo; Cuidador temporário; e Adotante.

Nome, celular, e-mail, disponibilidade de horários e dias da semana, $\mathrm{CNH}$, disponibilidade de regiões para a carona.

Nome, celular, lar temporário, dias da semana e horários disponíveis para receber animais resgatados, pode cuidar de animais doentes?, outras restrições para receber e manter animais resgatados.
Animal

Status do animal

Estado de saúde

\section{Animal}

Nome, raça, pelagem, sinais característicos, estado de saúde, idade aproximada, sexo, status, lar temporário, lar adotivo, vermifugado (data e quantidade de doses), castrado, vacinado, testado de doenças, causa da morte, data da morte, irmãos, mãe.

Não capturado, capturado, em lar temporário, em tratamento, divulgado para adoção, adotado, desaparecido, falecido.

Membro machucado? Está espirrando? Parece magro? Parece sentir dor? Está miando ou com semblante ruim? Está sangrando? É deficiente? Consegue comer sozinho? Consegue fazer as necessidades fisiológicas sozinho? Consegue se limpar sozinho? Positivo em algum teste de doença? Outros. 
Tabela 1. Dicionário de dados do processo de resgate e adoção.

\section{Resgate}

Pedido de resgate

Status do pedido

Resposta do pedido

Resgate

Transporte de animais
Informações do autor (nome, telefone, e-mail), localização (ponto de referência, setor, descrição, indicação no mapa, latitude e longitude), estado de saúde do animal, idade aproximada, está grávida?, filhote com mãe?, é agressivo?, foto e/ou vídeo do animal, responsável por atender, status, resposta, animais.

Não avaliado, avaliado positivamente, avaliado negativamente, suspenso, atendido, cancelado.

Positiva/negativa, justificativa, quem respondeu o pedido

Animais, data do resgate, local do resgate, hora do resgate, responsáveis pelo resgate, materiais utilizados, transporte dos animais.

\section{Transporte de animais}

Motorista solidário ou transporte por aplicativo, membro do projeto, animais, data, horário, origem, destino, tipo de atividade (pedido de resgate | atendimento veterinário | mudança de lar temporário | adoção | devolução ao local de resgate), atividade.

\section{Lar temporário}

\section{Cuidado temporário}

\section{Lar temporário}

\section{Solicitação de mudança} de lar temporário

\section{Status da solicitação}

Mudança de lar temporário
Responsável pela entrega, animais, lar temporário, cuidador temporário, data de recepção, data de saída, prazo máximo previsto, materiais utilizados.

Localização (endereço, complemento, bairro, cidade); é telado?, quais animais já tem em casa?, é possível isolar animais resgatados?

Cuidador temporário, motivo, animais, data de solicitação, status

Não planejada, planejada, atendida, cancelada.

Lar de origem, lar de destino, data, membro do projeto, animais 
Tabela 1. Dicionário de dados do processo de resgate e adoção.

\section{Atendimento veterinário}

Atendimento veterinário

Data, médico veterinário, custo, tipo de atendimento (consulta, castração, teste de doença, cirurgia), animais

\section{Divulgação de animais para adoção}

Divulgação de animais para adoção

Animais para adoção
Membro da equipe de resgate, animais para adoção, data da solicitação, data da divulgação, data de suspensão, motivo de suspensão, texto de apresentação

Nome dos animais, sexo, idade aproximada, vermifugados?, castrados?, foi feito teste de doenças?, estado de saúde, fotos

\section{Adoção}

Adoção

Lar adotivo
Responsável pela entrega, animais, lar adotivo, adotante, data prevista, data de adoção

Localização (endereço, complemento, bairro, cidade/estado); é telado?, prazo para telar (1 semana), quais animais já tem em casa?, é possível isolar animais resgatados?

Além de uma boa compreensão do processo de resgate e adoção e de informações utilizadas neste processo, outro resultado importante deste estudo foi a definição de 41 requisitos funcionais que um artefato digital deveria ter para apoiar adequadamente tal processo. Como desenvolver um artefato com tantos requisitos pode exigir muitos recursos, decidiu-se priorizar um conjunto inicial de requisitos para compor uma versão MVP (MinimumViableProduct ou, em português, Produto Mínimo Viável) desse artefato digital com maior celeridade. Foram priorizados 21 requisitos funcionais de modo que 0 MVP apoie a realização de atividades essenciais do processo de resgate e adoção de animais. Por restrições de espaço, apenas os requisitos priorizados são apresentados na Tabela 2. 
Tabela 2. Requisitos priorizados para um MVP do artefato digital de apoio ao resgate e adoção de animais.

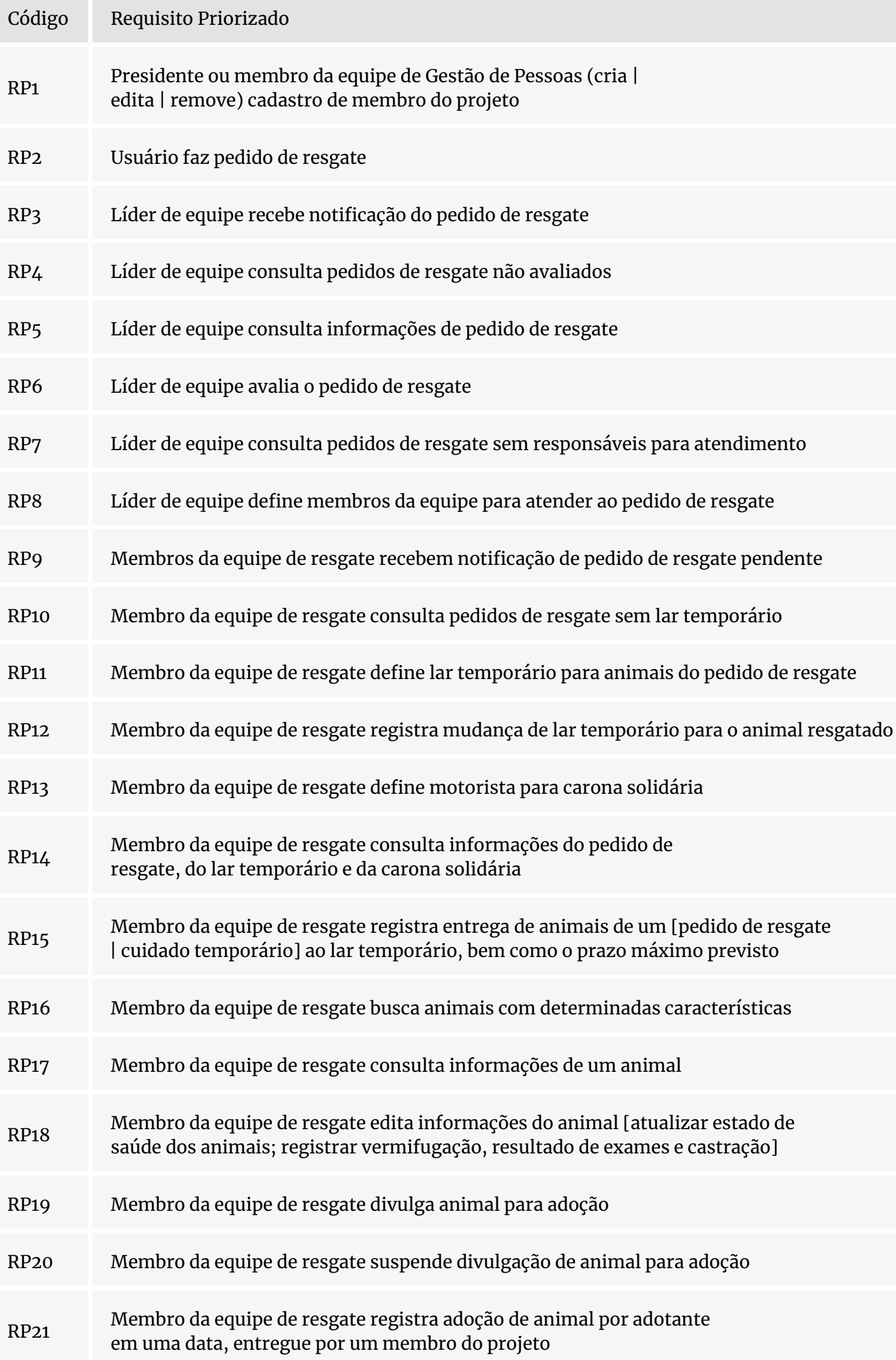


Nesta sessão foi descrito apenas o resultado final do estudo de caso. Aqueles interessados em acompanhar e entender em detalhes a evolução das atividades intermediárias deste estudo de caso devem consultar o estudo original (entrar em contato com autores). Lá também é possível encontrar a lista completa dos 41 requisitos funcionais identificados para o artefato digital.

\section{CONSIDERAÇÕES FINAIS}

Animais domésticos vivendo na rua aumentam as chances de propagação de doenças, inclusive para as pessoas, e são mais expostos a situações de maus tratos. Grupos informais e ONGs têm se engajado em um trabalho colaborativo de resgate e adoção de animais para evitar essas situações indesejadas. Trabalhos anteriores em design já buscaram contribuir com a causa animal. Eles se concentram no design de marcas (CUNHA, 2016; BRAUN; GOMEZ, 2010) ou no design de sites de ONGs (PONZI, 2015; CORRÊA; SANCHES, 2015) e de denúncias de maus-tratos (MARQUES, 2018). Pouca atenção tem sido dada à gestão do trabalho colaborativo realizado durante o resgate e adoção de animais por grupos informais ou ONGs.

Este trabalho tem por objetivo contribuir com o design de um artefato digital que possa apoiar a gestão do trabalho colaborativo no processo de resgate e adoção de animais. Para que o designer tenha condições adequadas de projetar um artefato digital, ele precisa conhecer vários elementos envolvidos (GARRETT, 2013; BARBOSA; SILVA, 2010; SILVA, 2010). Os objetivos dos usuários e as informações relacionadas com esses objetivos são elementos que se destacam nesse aprendizado necessário. Então, este trabalho relatou um estudo de caso que buscou compreender em profundidade as atividades e as informações no processo de resgate e adoção de animais. O estudo foi realizado com a elaboração de fluxogramas e dicionário de dados, discutidos e aprimorados em grupos focais com a participação de pessoas envolvidas num projeto de extensão universitária para o resgate e adoção de animais de rua. Com 
base neste aprendizado, enunciou-se 41 requisitos funcionais para o artefato digital, bem como uma priorização de 21 requisitos funcionais para compor o produto viável mínimo (MVP).

$O$ aprendizado sobre atividades e informações e os requisitos funcionais apresentados neste trabalho são uma contribuição importante para quem for projetar um artefato digital de apoio à gestão do trabalho colaborativo no processo de resgate e adoção de animais. Isso pode ajudar tanto designers concebendo novos artefatos digitais, quanto designers que pretendem propor melhorias a um artefato digital existente.

\section{REFERÊNCIAS BIBLIOGRÁFICAS}

BARBOSA, S.D.J.; SILVA, B.S.Interação Humano-

Computador. Série SBC- Campus. Elsevier, 2010.

BONSIEPE, Gui. Do material ao

digital. Editora Blucher, 2015.

BRASIL. Presidência da República. Decreto-Lei

$\mathbf{N}^{\circ} \mathbf{2 . 8 4 8}$, de 7 de dezembro de 1940. Disponível

em: <http://www.planalto.gov.br/ccivil_03/decreto-lei/

Del2848compilado.htm> Acesso em: 24 ago. 2020.

BRAUN, J.R.R.; GOMEZ, L.S.R. O Design Gráfico e a Gestão de Marcas de ONGs Ambientalistas: resultados

preliminares. In: e-Revista LOGO, v. 1, n. 1, p. 76-81, 2010.

CLUBE DOS VIRA-LATAS. Clube dos Vira-Latas, 2021.

Disponível em: <http://www.clubedosviralatas.

org.br>. Acesso em: 5 fev. 2021.

CORRÊA, B.A.; SANCHES, E.C.P. Uma pata de cada vez:

website de apoio a instituições filantrópicas de cuidado animal. TCC (Bacharelado em Design) - Departamento Acadêmico de Desenho Industrial, Universidade Tecnológica Federal do Paraná. Curitiba, 2015. 
COURAGE, C.; BAXTER, K. Understanding your

users: a practical guide to user requirements, methods, tools, and techniques. San Francisco, CA: Morgan Kaufmann Publishers, 2005.

CUNHA, B.C. Gestão da Identidade Visual para ONGs.

TCC (Bacharelado em Programação Visual)- Departamento de Design, Universidade de Brasília. Brasília, 2016.

FUKS, H.; PIMENTEL, M. Sistemas Colaborativos.

Rio de Janeiro: Elsevier, 2012.

GARRET, J. J. The elements of user experience.

Berkeley, CA: New Riders, 2011.

INSTITUTO LUISA MELL. Instituto LuisaMell de Assistência aos Animais e Meio Ambiente, 2020. Disponível em: <http://ilm.org.br>. Acesso em: 5 fev. 2021.

INSTITUTO PET BRASIL. País tem 3,9 milhões de animais em condição de vulnerabilidade. 2019.

Disponível em: <http://institutopetbrasil.com/imprensa/ pais-tem-39-milhoes-de-animais-em-condicaode-vulnerabilidade>.Acesso em: 25 jan. 2021.

JAGHER, D.; GONÇALVES, M.V.; BUENO, J. Lambeijos: sistema de busca e adoção de animais. Anais do $9^{\circ}$ Congresso Internacional de Design da Informação (CIDI). p. 2695-2703. 2019.

JOFFILY, D.; DE SOUZA, L. M.; GONÇALVES, S. M.; PINTO, J. V.; BARCELLOS, M. C. B.; ALONSO, L. DA S. Medidas para o controle de animais errantes desenvolvidas pelo grupo PET Medicina Veterinária da Universidade Federal Rural do Rio de Janeiro. RevistaEmExtensão, v. 12, n. 1, 19 jul. 2013.

LAWSON, B.R. How Designers Think: The Design

Process Demystified, Fourth Edition. Elsevier, 2006. 
MARQUES, B.F.C. Animalia: Proposta de aplicação web voltada para defesa e amparo de animais domésticos.TCC (Bacharelado em Comunicação Visual Design) - Escola de Belas Artes, Universidade Federal do Rio de Janeiro. Rio de Janeiro, 2018.

MENDES, G.C.; PEIXOTO, J.A.F.; PASSOS, M.G. Design de interface de web app colaborativo para assistência a animais necessitados. TCC (Bacharelado em Design Gráfico) - Faculdade de Artes Visuais, Universidade Federal de Goiás. Goiânia, 2016.

MORAES, A.; MONT'ALVÃO, C. Ergonomia: conceitos e aplicações. 4. ed. Rio de Janeiro: 2AB, 2009.

NUNES, P.S. Website para ONG AMAHTEB: Animais abandonados. Trabalho de Conclusão de Curso de Design Gráfico. Universidade Tecnológica Federal do Paraná. 2014.

PONZI, J.C.Design gráfico de websites de ONGs de proteção aos animais domésticos. Revista Imagem, v. 5, n. 1, p. 82-102, 2015.

SANTOS, P. Algumas questões relativas ao encaminhamento de cães e gatos para adoção. Revista de Antropologia da UFSCAR, v. 7, n. 1, p. 230-247, 2015.

SCHÖN, D.A. The ReflectivePractitioner.

New York: Basic Books, 1983.

SILVA FILHO, G.L.F. Desenvolvimento de Aplicativo Para Adoção de Animais Abandonados Utilizando a Linguagem de Programação Kotlin e Programação

Reativa. TCC (Bacharelado em Engenharia da Computação)

- Departamento Acadêmico de Informática, Universidade Tecnológica Federal do Paraná. Curitiba, 2017. 
SILVA, B. S. O uso de Casos na Reflexão em Ação em atividades de Design de IHC.Tese (Doutorado em Informática). Departamento de Informática, Pontifícia Universidade Católica do Rio de Janeiro. Rio De Janeiro, 2010.

SILVA, D.O.; FRANÇA JUNIOR, J.L.O.P.; TAVARES, R.S. Solução de design digital para o problema dos animais abandonados. Revista Sistemas e Mídias Digitais. v. 4, n. 2, p. 1-18, 2019.

SILVA, R.L.P. Pet Adoto: Projeto de Interface de Aplicativo para Adoção de Animais. TCC (Bacharelado em Comunicação Visual Design) - Escola de Belas Artes, Universidade Federal do Rio de Janeiro. Rio De Janeiro, 2016.

WIEGERS, K.; BEATTY, J.Software Requirements.

3rd Edition, Microsoft Press, 2013.

WORLD ANIMAL PROTECTION. Na Paraíba, Proteção

Animal Mundial discute soluções para o abandono

de cães e gatos. 2019. Disponível em: <https://www. worldanimalprotection.org.br/ not\%C3\%ADcia/naparaiba-protecao-animal-mundial-discute-solucoes-parao-abandono-de-caes-e-gatos> Acesso em: 25 jan. 2021. 